\title{
ПРАВОВЫЕ ВОПРОСЫ
}

\section{Россия ратифицировала Соглап̈ение ФАО \\ - мерах государства порта по бopьбe с HНH рыбным промыслом 2009 года}

DOI

Заслуженный деятель

науки РФ, д-р юрид. наук, профессор К.А. Бекяшев советник Руководителя

Росрыболовства;

д-р юрид. наук, профессор Д.К. Бекяшев - Московский государственный институт международных отношений (университет) Министерства иностранных дел

Российской Федерации (МГИМО МИД России)

@profbek@mail.ru; dambek@yandex.ru

Ключевые слова: Соглашение 2009 г.; ФАО; ННН рыбный промысел; меры государства порта; Российская Федерация; ратификация; законодательство; совершенствование

Keywords:

2009 Agreement; FAO; IUU fishing; port state measures; Russian Federation; ratification; legislation; improvement

RUSSIA RATIFIED THE FAO AGREEMENT

ON PORT STATE MEASURES TO COMBAT IUU FISHING 2009

Honored Worker of Science of the Russian Federation, Doctor of Juridical Sciences, Professor K.A. Bekyashev - adviser to the Head of the Federal Agency for Fisheries; Doctor of Juridical Sciences, Professor D.K. Bekyashev - Moscow State Institute of International Relations (MGIMO MFA Russia),profbek@mail.ru; dambek@yandex.ru

The article examines the history of the development of the 2009 Agreement, analyzes in detail its main provisions. Taking into account the accession of the Russian Federation to this international treaty, recommendations and proposals for improving Russian legislation are prepared.

Президент Российской Федерации В.В. Путин 8 декабря 2020 г. подписал Федеральный закон «О ратификации Соглашения о мерах государства порта по предупреждению, сдерживанию и ликвидации незаконного, несообщаемого и нерегулируемого промысла» (далее - Соглашение 2009 г.). Согласно ст. 29, указанного международного договора, он вступает в силу для Российской Федерации через 30 дней после сдачи на хранение его документа о ратификации депозитарию, которым является Генеральный директор ФАО.

Таким образом, положения данного международно-правового акта становятся обязательными для нашей страны. В связи с этим, представляется целесообразным рассмотреть ключевые нормы Соглашения 2009 г. и провести сравнительно-правовой анализ этого международного договора и действующего законодательства Российской Федерации.

\section{КРАТКАЯ ИСТОРИЯ}

РАЗРАБОТКИ ПРОЕКТА

СОГЛАШЕНИЯ 2009 ГОДА

Согласно Целям устойчивого развития 14.4 и 14.6, в 2020 г. должен быть прекращен незаконный, несообщаемый и нерегулируемый рыбный промысел (НHН рыбный промысел). В ЦУР 14 рассматриваются основные достижения в применении международных документов и принятии новых. Международное сообщество активно стимулирует борьбу с НHН рыбным промыслом. В результате такого промысла, объемы которого достигают мил- 
лионов тонн в год (по данным ФАО, примерно 20 млн т), мировая экономика теряет ежегодно несколько миллиардов долларов США.

Одним из первых международных документов, направленных на предотвращение ННН рыбного промысла, является Соглашение о мерах государства порта по предупреждению, сдерживанию и ликвидации незаконного, несообщаемого и нерегулируемого промысла 2009 года. В настоящее время оно является единственным универсальным международным договором, направленным непосредственно на борьбу с ННН рыбным промыслом.

Это Соглашение было одобрено Конференцией ФАО 22 ноября 2009 года. Сразу же после его одобрения оно было открыто для подписания в течение одного года. Соглашение вступило в силу 5 июня 2016 года. В Соглашении 2009 г. участвуют 62 государства. Оно было разработано по инициативе ФАО, в соответствии со ст. XIV Устава ФАО, которая гласит: «Конференция может принять решение большинством в 2/3 поданных голосов, в соответствии с правилами, принятыми Конференцией, одобрить и направить государствам-членам конвенции и соглашения, касающиеся вопросов продовольствия и сельского хозяйства.

На специальном мероприятии высокого уровня по случаю вступления Соглашения 2009 г. в силу, проходившем в рамках 32-й сессии Комитета по рыболовству ФАО в июне 2016 г., Генеральный директор ФАО Жозе Грациано да Силва отметил, что будущие поколения оценят важность этого достижения. Он выразил надежду, что все больше и больше стран присоединятся к этому Соглашению и тем самым продемонстрируют свою приверженность международно-правовым принципам и принципам устойчивого рыболовства. По словам Генерального директора ФАО, на глобальном уровне объем ежегодного НHНпромысла достиг 26 млн т, стоимостью до 23 млрд долл. США. ННН-промысел ставит под угрозу не только морские экосистемы, но и лишает источников средств к существованию и продовольствию миллионы рыбаков по всему миру. Президент Республики Гвинея Альфа Конде в своем выступлении подчеркнул, что незаконный лов рыбы угрожает не только мировой торговле, но и создает реальную угрозу для продовольственной безопасности и питания в Африке, где серьезно обеспокоены распространенной практикой ведения ННН-промысла в африканских водах. В свою очередь, Генеральный директор Директората по морским делам и рыболовству Европейской комиссии Жоао Агуиар Мачадо, выступая от имени 28 стран-членов ЕС, отметил приверженность Союза борьбе с ННН-промыслом, а также призвал страны вносить взносы в Целевой фонд (согласно ст. 21 Соглашения 2009 г.), который будет оказывать помощь развивающимся странам для выполнения ими обязательств по Соглашению о мерах государства порта [1].

Как заметил Генеральный директор ФАО Жозе Грациано да Силва, Соглашение 2009 г. предусматривает минимальный набор стандартных мер
В статье рассмотрена история разработки Соглашения 2009 г., подробно проанализированы его основные положения. С учетом присоединения Российской Федерации к этому международному договору, подготовлены рекомендации и предложения по совершенствованию российского законодательства.

для государства порта, применяемых при заходе в порт иностранных судов или их стоянке в порту. По мнению главы ФАО, благодаря применению определенных процедур и других инспекционных и обеспечивающих соблюдение закона мер, с целью проверки, не занимались ли такие суда $\mathrm{HHH}$ рыбным промыслом, можно предотвратить поступление на национальные и международные рынки рыбы, выловленной в результате незаконного, несообщаемого и нерегулируемого промысла рыбного промысла, лишая тех, кто в нем участвует, возможностей продолжать такого рода деятельность. Эффективное применение Соглашения 2009 г. требует наличия действенных политических, правовых, институциональных и оперативных механизмов [2].

Безусловно, Соглашение 2009 г. само по себе не может решить глобальные проблемы НHНпромысла. Они должны рассматриваться комплексно и по отдельности, взаимно дополнять друг друга. Однако, блокируя движение НHН выловленной рыбы в портах и на национальных и международных рынках, а также контроль за деятельностью судов, занятых в ННН-промысле, должны создать трудности для незаконного промысла и сохранить рентабельность, как стимул для рыбаков, продолжать участие в таком рентабельном промысле и связанной с этим деятельности [3].

Соглашение 2009 г. состоит из преамбулы, 37 статей и 4 приложений. Рассмотрим его ключевые положения.

\section{ПРЕАМБУЛА СОГЛАШЕНИЯ 2009 ГОДА}

Преамбула Соглашения 2009 г. содержит ряд принципиальных положений, которые подлежат комментированию.

Во-первых, в преамбуле указано, что государства вправе, при осуществлении своего суверенитета над портами, расположенными на их территории, принимать более строгие меры в соответствии с международным правом. Возникают вопросы: а) какие меры?; б) более строгие меры по сравнению с какими мерами?; в) предусмотрены ли в международном праве такие меры?

Согласно ст. 11 Конвенции ООН по морскому праву 1982 г. порты и постоянные портовые сооружения рассматриваются как часть берега. Следовательно, на них в полной мере распространяется суверенитет прибрежного государства.

В 1923 г. в рамках Международного морского комитета была разработана Конвенция о режиме судов в иностранных портах. Но она в силу не вступила.

О правовом статусе иностранных судов в портах прибрежных государств упоминается в ряде конвенций ИМО, например, в Конвенции о предотвращении загрязнения моря нефтью 1973 г., 
в Конвенции об охране человеческой жизни на море 1972 г., а также в Парижском, Токийском, Карибском, Африканском меморандумах [4].

Так, в Парижском меморандуме 1982 г. регламентирован отказ в заходе судов в порты или на рейдовые стоянки. Такой отказ может быть запрещен, если судно несет флаг государства, находящегося в сером списке, вследствие нарушения норм по безопасности мореплавания (раздел 4).

Некоторые вопросы статуса и обязанностей иностранных судов в портах предусмотрены также в Конвенции МОТ о труде в морском судоходстве 2006 г. и Конвенции МОТ о труде в рыболовном секторе 2007 года. В частности, пункт 2 ст. 43 Конвенции 2007 г. позволяет государству, в порт которого заходит иностранное рыболовное судно, принимать меры, необходимые для улучшения условий на борту судна, которые явно представляют угрозу для безопасности и здоровья рыбаков. В целом, отметим, что в принимаемых в последнее время международно-правовых актах, прослеживается четкая тенденция, которая позволяет государству, в порт которого заходят те или иные суда иностранных государств, принимать в отношении них меры, если идет речь о безопасности людей, находящихся на борту таких судов [5].

В преамбуле Соглашения 2009 г. указывается на то, что в нем учтены соответствующие положения Конвенции ООН по морскому праву 1982 г., Соглашения о трансграничных рыбных запасах и запасах далеко мигрирующих видов 1995 г., Соглашения о содействии соблюдению рыболовными судами в открытом море международных мер по сохранению живых ресурсов и управлению ими 1993 г., Кодекса ведения ответственного рыболовства 1995 года. Возникает вопрос, о каких положениях идет речь?

Например, согласно ст. 21 Соглашения 1995 г. государство порта имеет право и обязано принимать, сообразуясь с нормами международного права, меры к тому, чтобы способствовать эффективности субрегиональных, региональных и всемирных мер по сохранению и управлению. При принятии таких мер государство порта не подвергает суда какого-либо государства формальной или фактической дискриминации.

Государство порта может, в частности, проверить документацию, орудия лова и улов на борту рыболовных судов, когда такие суда добровольно находятся в его портах или на его рейдовых причалах.

Государства могут принимать правила, уполномочивающие соответствующие национальные власти запрещать выгрузку и перевалку, когда было установлено, что улов получен таким образом, который подрывает эффективность субрегиональных, региональных или всемирных мер по сохранению и управлению в открытом море.

В других, перечисленных выше международноправовых актах, правовой режим портов в части захода судов не затрагивается.

Подчеркнем, что высший орган ООН - Генеральная Ассамблея уделяет самое пристальное внимание проблемам устойчивого рыболовства в Мировом океане. Среди этих проблем на первом месте, безусловно, находятся вопросы ННН рыб- ного промысла. Например, в своей Резолюции 74/18 «Обеспечение устойчивого рыболовства», принятой 10 декабря 2019 г., содержится раздел «Незаконный, несообщаемый и нерегулируемый рыбный промысел». В нем имеются соответствующие положения о Соглашении 2009 года.

Во-первых, Генеральная Ассамблея ООН одобрила ратификацию государствами этого Coглашения и рекомендовала государствам и региональным организациям экономической интеграции рассмотреть вопрос о его ратификации, принятии, одобрении или присоединении к нему, отмечая при этом важность того, чтобы его сторонами, при первой же возможности, становились крупные государства порта.

Во-вторых, Генеральная Ассамблея ООН поддержала программу ФАО по наращиванию потенциала по облегчению и поддержке содействия Соглашения 2009 г. и способствует тем самым формированию национального потенциала как у участвующих, так и у не участвующих в этом Соглашении стран, в том числе - укреплению институционального, оперативного и правоприменительного потенциала развивающихся стран, в целях получения максимальной выгоды от его реализации.

Генеральный секретарь ООН в своем докладе за 2019 г. «Мировой океан и морское право» поддержал усилия государств и ФАО по принятию глобальной системы обмена информацией относительно имплементации Соглашения 2009 года.

Преамбула Соглашения 2009 г. провозглашает принцип первоочередной ответственности государства флага в рамках международного права. Эта норма давно трансформировалась в общепризнанный принцип международного и рыболовного права.

В частности, согласно статье 217 Конвенции 1982 г., государства обеспечивают соблюдение судами, плавающими под флагом или зарегистрированными в них, применяемых международных норм и стандартов, установленных через международные организации.

Соглашение 1995 г. о трансграничных запасах подробно определяет обязанности государства флага. Государство, суда которого ведут рыбный промысел в открытом море, принимает необходимые меры к обеспечению того, чтобы суда, плавающие под его флагом, соблюдали субрегиональные и региональные меры по сохранению и управлению и чтобы такие суда не занимались какой бы то ни было деятельностью, подрывающей эффективность таких мер.

Государство флага должно осуществлять контроль за такими судами и обеспечивать, чтобы суда под его флагом не занимались ННН рыбным промыслом.

\section{ЦЕЛИ СОГЛАШЕНИЯ 2009 Г. \\ И ОСОБЕННОСТИ ЕГО ПРИМЕНЕНИЯ}

Целью Соглашения 2009 г. является предотвращение, сдерживание и ликвидация ННН рыбного промысла путем применения эффективных мер государства порта и таким образом обеспечение долгосрочного сохранения и устойчивого использования живых морских ресурсов и морских экоси- 
стем. Как явствует из вышеизложенного, государство порта должно принимать эффективные меры для предотвращения незаконного, несообщаемого и нерегулируемого промысла рыбного промысла. Однако ни в одной статье не дается его определения или хотя бы признаков этого понятия, что, безусловно, затрудняет применение его положений.

Каждая сторона в качестве государства порта применяет настоящее Соглашение 2009 г. в отношении судов, не уполномоченных находиться под ее флагом и запрашивающих доступ в ее порты или находятся в одном из ее портов, за исключением следующих 2-х случаев: а) судов какого-либо соседнего государства, занятых кустарным промыслом для обеспечения средств к существованию при условии, что упомянутые государства порта и государства флага сотрудничают в целях обеспечения или связанной с промыслом деятельностью в поддержку такого промысла; б) судов-контейнеров, которые не перевозят рыбу или в случае перевозки рыбы, то только ту, которая ранее была выгружена, при условии, что нет явных оснований предполагать, что эти суда были заняты промысловой деятельностью в поддержку ННН рыбного промысла.

Статья 3 предусматривает возможность исключения некоторых судов из действия Соглашения 2009 года. Так, любая Сторона в качестве государства порта может принять решение о неприменении Соглашения 2009 г. в отношении судов, зафрахтованных ее гражданами исключительно с целью ведения промысла в районах ее национальной юрисдикции.

Рассматриваемое Соглашение применяется к промыслу, проводимому в морских районах, который является незаконным, несообщаемым или нерегулируемым и к связанной с промыслом деятельности в поддержку такого промысла.

\section{ПРАВОВАЯ РЕГЛАМЕНТАЦИЯ ЗАХОДА СУДОВ В ПОРТЫ}

Согласно ст. 7 Соглашения 2009 г., каждая Сторона назначает порты, в которых суда могут запрашивать заход. Такое государство опубликовывает информацию о портах и направляет ее в ФАО.

Государство порта до представления какомулибо судну разрешения на заход в свой порт требует предоставления в качестве минимального стандарта следующую информацию: предполагаемый порт захода; государство порта; расчетные дату и время прибытия; цель; название порта и дата последнего захода в порт; название судна; государство флага; тип судна; свидетельство о регистрации; ID ИМО судах; внешний ID; ID РФМО; CMC; размер судна; имя и гражданство капитана судна; соответствующие разрешения; информацию о перегрузке; общий улов на борту.

После получения этой информации, а также дополнительной информации о том, было ли это судно занято в ННН рыбном промысле, Сторона порта принимает решение о разрешении или отказе на заход в порт такого судна и сообщает об этом судну или его представителю.

Однако государство порта может разрешить заход в свои порты судну в целях проведения ин- спекции данного судна и принятии иных соответствующих действий в соответствии с международным правом.

Если судно находится в порту по какой-либо другой причине, Сторона отказывает такому судну в использовании ее портов для выгрузки, перегрузки, упаковки и переработки рыбы и для иного портового обслуживания, включая пополнение топливом и запасами, ремонт и постановку на сухой док (речь, например, идет о суднах, включенных в список ННН рыбного промысла).

Однако нельзя отказать в заходе судна при форс-мажорных обстоятельствах или бедствии.

\section{ПОРЯДОК ИСПОЛЬЗОВАНИЯ ПОРТОВ}

Статья 11 Соглашения 2009 г. позволяет отказывать судну в использовании порта для выгрузки, перегрузки, упаковки и переработки рыбы, которая ранее не выгружалась, и для иного портового обслуживания, включая, помимо прочего, пополнение топливом и запасами, ремонт и постановку в сухой док, если:

a) Сторона обнаруживает, что данное судно не имеет действующего и применимого разрешения на ведение промысла или связанной с промыслом деятельностью, требуемого его государством флага;

б) Сторона обнаруживает, что данное судно не имеет действующего и применяемого разрешения на ведение промысла;

в) Сторона получает явное доказательство того, что находящаяся на борту рыба была выловлена в нарушение соответствующих требований прибрежного государства в отношении районов, находящихся под национальной юрисдикцией данного государства;

г) Государство флага не подтверждает в течение разумного периода времени по запросу государства порта, что находящаяся на борту рыба была выловлена в соответствии с применяемыми требованиями соответствующей РФМО с должным учетом соответствующих требований Соглашения 2009 года;

д) Сторона имеет разумные основания полагать, что данное судно иным образом участвовало в ННН рыбном промысле или связанной с промыслом деятельностью в поддержку такого промысла.

\section{ПОРЯДОК ПРОВЕДЕНИЯ ИНСПЕКЦИИ И ЕЕ ПОСЛЕДСТВИЯ}

Каждая Сторона инспектирует такое количество судов в своих портах, которое требуется для достижения годового уровня инспекций, достаточного для достижения цели Соглашения 2009 года.

При определении того, какие суда инспектировались, Сторона прежде всего обращает внимание на:

a) суда, которым было отказано в заходе в порт или его использовании;

б) запреты других соответствующих Сторон, государств или РФМО об инспектировании определенных судов, особенно если такие запросы сопровождаются доказательством ведения ННН рыбного промысла или связанной с промыслом деятельности в поддержку такого промысла данным судном; 
в) иные суда, в отношении которых имеются явные основания предполагать, что они были заняты ННН рыбным промыслом или связанной с промыслом деятельностью в поддержку такого промысла.

Каждая Сторона при проведении инспекции:

a) проводит ее инспекторами, имеющими соответствующую квалификацию и уполномоченными для этой цели;

б) обеспечивает, чтобы до проведения осмотра инспекторы предъявляли капитану судна соответствующий документ, удостоверяющий инспекторов как таковых;

в) обеспечивает, чтобы инспекторы проверяли все соответствующие помещения на судне, находящуюся на борту рыбу, сети и любые иные орудия лова, оборудование и любой документ или записки, имеющиеся на борту, уместные для подтверждения соблюдения соответствующих мер по сохранению и управлению;

г) требует от капитана судна предоставления инспекторам необходимого содействия и информацию, а также предъявления соответствующих материалов и документов, которые могут потребоваться как их заверенных копий;

д) в случае соответствующих договоренностей с государством флага данного судна, предлагают данному государству участвовать в инспекции;

е) прилагает все возможные усилия для избегания необоснованной поддержки судна с целью сведения до минимума вмешательства и неудобства, включая любое присутствие инспекторов на борту, не обусловленное необходимостью, а также избегания действия, которое могло бы негативно повлиять на качество рыбы на борту;

ж) прилагает все возможные усилия для содействия связи с капитаном или старшим командным составом экипажа, в том числе, если это возможно и необходимо, сопровождение инспектора переводчиком;

3) обеспечивает, чтобы инспекции проводились справедливым, открытым и недискриминационным образом и не представляли бы собой беспокоящие действия в организации какого-либо судна;

и) не препятствует возможности капитана, согласно международному праву, связаться с властями государства флага.

Отметим, что четкое закрепление в законодательстве государств полномочий инспекторов при осмотре иностранных рыболовных судов - один из ключевых вопросов. Даже правильно обученные инспекторы могут действовать эффективно лишь при наличии у них соответствующих юридических полномочий [6].

Результаты инспекции излагаются в письменном отчете, который включает в себя около 50 пунктов. В частности, в нем указывается имя основного инспектора, начало и завершение инспекции, название судна, государство флага, порт приписки, владелец судна, имя и гражданство капитана, оценка выгруженного улова, проверка промыслового журнала.

Сторона передает результаты каждой инспекции государству флага, а также государству, гражданином которого является капитан судна, соответствующим региональным ведомствам по управлению рыболовством, ФАО и иным международным организациям.

Если после проведения инспекции имеются явные основания полагать, что судно принимало участие в ННН рыбном промысле или связанной с промыслом деятельностью в поддержку такого промысла, то инспектирующая Сторона:

а) незамедлительно уведомляет государство флага и, если уместно, соответствующие прибрежные государства, РФМО, а также государство, гражданином которого является капитан данного судна, о своих выводах;

б) отказывает судну в использовании своего порта для выгрузки, перегрузки, упаковки и переработки рыбы, которая ранее не была выгружена, и для иного портового обслуживания, включая, помимо прочего, пополнение топливом и запасами, ремонт и постановку в сухой док, если эти меры уже не были приняты в отношении данного судна таким образом, который соответствует Coглашению 2009 года.

Однако, независимо от этого, Сторона не отказывает вышеотмеченному судну в пользовании портовыми услугами, имеющими существенное значение для безопасности и здоровья экипажа или безопасности судна.

Рассматриваемое Соглашение предусматривает право владельцу, капитану или представителю судна обратиться в суд своего государства с исковым заявлением в отношении государства порта.

\section{РОЛЬ ГОСУДАРСТВА ФЛАГА}

В соответствии со ст. 20 Соглашения 2009 г., каждая Сторона предписывает судам, имеющим право находиться под ее флагом, сотрудничать с государством порта в ходе инспекций, проводимых в соответствии с этим Соглашением.

Если Сторона имеет явные основания полагать, что судно, имеющее право находиться под ее флагом, было занято ННН рыбным промыслом или связанной с промыслом деятельностью в поддержку такого промысла и запрашивает заход или находится в порту другого государства, то данная Сторона при необходимости запрашивает это государство об инспектировании указанного судна или о принятии иных мер в соответствии с Соглашением 2009 года.

Основные обязанности государства флага изложены в ст. 20 Соглашения 2009 г. и заключаются в следующем.

Каждая Сторона обеспечивает, чтобы суда, имеющие право находиться под её флагом, занимались выгрузкой, перегрузкой, упаковкой и переработкой рыбы и получали иное портовое обслуживание в портах государств, действующих согласно Соглашению 2009 г. или способом, соответствующим ему. Стороны призываются разработать, в том числе в рамках региональных организаций по управлению рыболовством и ФАО, справедливый, открытый и недискриминационный порядок идентификации государств, которые могут действовать 
не в соответствии с Соглашением 2009 г. или способом, не соответствующим ему.

Каждая Сторона в качестве государства флага сообщает иным Сторонам, соответствующим государствам порта и, если это уместно, другим соответствующим государствам, региональным организациям по управлению рыболовством и ФАО о действиях, предпринятых в отношении судов, имеющих право находиться под ее флагом, которые в результате мер государства порта выявлены в качестве принимающих участие в ННН рыбном промысле или связанной с промыслом деятельности в поддержку такого промысла.

\section{УРЕГУЛИРОВАНИЕ СПОРОВ}

В части 7 Соглашения 2009 г. перечислены средства разрешения споров, которые корреспондируются со ст. 33 Устава ООН. Такими средствами являются консультации спорящих Сторон, переговоры, посредничество, примирение, арбитраж, правовое разбирательство или иные средства.

Любой спор такого рода, не разрешенный указанными выше средствами, может быть передан в Международный суд ООН, Международный трибунал по морскому праву или арбитраж.

Соглашение 2009 г. подлежит ратификации, принятию или одобрению подписантами. Как было сказано выше, в этом Соглашении участвуют 62 государства и ЕС.

Отметим, что некоторые государства-участники Соглашения 2009 г. приняли развернутые законодательные акты, которые вытекают из обязательств, закрепленных в этом международном договоре.

Например, в США принят Кодекс, в главе 16 которого изложена позиция США по некоторым положениям Соглашения 2009 года. Министр торговли или кто-то от его имени назначает и публикует порты, в которые суда могут войти. Он предоставляет уведомление об отказе в заходе в порт или использование портовых услуг.

Министр может запросить у государства флага иностранного судна подтверждение того, что рыба на борту такого судна, находящегося в порту, была выловлена в соответствии с, применимыми региональными организациями по управлению рыболовством, мерами по сохранению и управлению.

Судно, стремящееся войти в порт США, должно предоставить Департаменту береговой охраны информацию до своего прибытия в порт. На основе этой информации Департамент принимает решение о разрешении или запрещении захода судна в порт.

Департамент береговой охраны может отказать в заходе судна в порт, если: судно внесено в список ННН-судов, или у министра торговли есть разумные основания полагать, что судно участвовало в ННН рыбном промысле или связанной с рыболовством деятельностью в поддержку такого промысла; судно вошло в порт без разрешения; государство флага судна не предоставило подтверждение, запрошенное Департаментом, что рыба на борту была выловлена в соответствии с применимыми мерами региональных организаций по управлению рыболовством; находящаяся на борту рыба была выловлена в нарушение зако- нодательства любого государства или мер, принятых региональными организациями по управлению рыболовством.

В Кодексе США имеется ряд положений, которых в Соглашении 2009 г. нет. Например, согласно §7407 (1) любое иностранное судно (включая рыболовные снасти, оборудование, мебель и грузы) и любая рыба, импортируемая или находящаяся во владении, в связи или в результате совершения какоголибо действия, запрещенного Кодексом, подлежат конфискации согласно пункту 1860 этого Кодекса.

\section{РОССИЙСКАЯ ФЕДЕРАЦИЯ И СОГЛАШЕНИЕ 2009 ГОДА}

В Российской Федерации уделяется большое внимание вопросам охраны водных биоресурсов. В частности, реализуется, утвержденный распоряжением Правительства России от 25 декабря 2013 г. № 2534-р, национальный план действий по предупреждению, сдерживанию и ликвидации незаконного, несообщаемого и нерегулируемого промысла. Этот план предусматривает развитие международного сотрудничества в области противодействия ННН рыбному промыслу, усиление административных и уголовных санкций. Среди мер, реализуемых в рамках национального плана - система подтверждения законности происхождения уловов и продукции из них, вывозимых из России и ввозимых в нашу страну [7].

Российская Федерация принимала активное участие в разработке проекта Соглашения 2009 года. Один из авторов данной статьи - К.А. Бекяшев был членом Рабочей группы ФАО по подготовке концепции этого Соглашения и его ключевых статей.

Отметим, что Россия подписала указанное Coглашение 29 апреля 2010 года. Однако для вступления в силу для нашей страны этого было недостаточно, поскольку необходима была его ратификация. Потребовалось чуть более 10 лет, чтобы наша страна осуществила эту процедуру.

Поскольку для Российской Федерации Соглашение 2009 г. теперь является юридически обязательным, возникает вопрос: соответствует ли ему действующее российское законодательство?

1. Кодекс торгового мореплавания 1999 г. (КТМ РФ). В ст. 76 этого Кодекса перечислены функции капитана морского порта. Разумеется, функций по обеспечению выполнения Соглашения 2009 г. в ней нет. В этой связи следует принять Федеральный закон о дополнении ст. 76 КТМ РФ следующим абзацем: «дает разрешения на заход иностранных рыболовных судов в порт и выход из морского порта, в соответствии с Соглашением о мерах государства порта по предупреждению, сдерживанию и ликвидации незаконного, несообщаемого и нерегулируемого промысла от 22 ноября 2009 года».

2. Федеральный закон «О морских портах в Российской Федерации» 2007 года. В целях имплементации Соглашения 2009 г. предлагается в этот закон внести следующие дополнения:

- в ст. 8 внести следующее дополнение: «Государственное регулирование деятельности в морском порту осуществляется в целях обеспечения: 
11) предотвращения незаконного, несообщаемого и нерегулируемого рыбного промысла;

- в п. 1 ст. 8.1 после слов «охраны окружающей среды» добавить «предотвращения ННН рыбного промысла»;

- статью 11, в которой говорится о функциях капитана морского порта дополнить новым пунктом: «принимает в пределах законодательства Российской Федерации меры по предотвращению ННН рыбного промысла».

Кроме того, по словам руководителя Росрыболовства И.В. Шестакова, «требуется внести поправки в Федеральный закон о морских портах в Российской Федерации в части о наделении Росрыболовства полномочиями ведения национального списка ННН-судов и координирующего центра для прямого международного обмена информацией с региональными организациями по регулированию рыболовства в части выполнения Соглашения» [8].

3. Ф3 «О внутренних морских водах, территориальном море и прилежсащей зоне Российской Федерации» 1998 года. Данный нормативный правовой акт регламентирует порядок захода иностранных судов в российские морские порты (ст. 6). На наш взгляд, в данной статье следует отразить особенности захода иностранных рыболовных судов в соответствии с Соглашением 2009 года.

В ФЗ «О внутренних морских водах, территориальном море и прилежащей зоне Российской Федерации» следует предусмотреть возможности отказа в заходе в морской порт или постановке на якорь на подходах к морскому порту иностранного судна, оборудованного для использования на промысле или связанного с промысловой деятельностью, в случае если его участие в ННН рыбном промысле доказано.

4. ФЗ «О рыболовстве и сохранении водных биологических ресурсов» 2004 года. В базовом законе практически нет ни слова о предотвращении ННН рыбного промысла. После ратификации Российской Федерацией Соглашения 2009 г. в данный Федеральный закон необходимо включить главу под условным названием «Предупреждение, сдерживание и ликвидация незаконного, несообщаемого и нерегулируемого рыбного промысла». В дальнейшем необходим самостоятельный федеральный закон, касающийся предотвращения ННН рыбного промысла.

Помимо указанных дополнений в федеральные законы, следует также разработать и утвердить дополнения и изменения на уровне Правительства Российской Федерации. Например, таковыми могут быть утвержденные постановлениями Кабинета министров инструкции о порядке захода судов в морские порты: порядок подачи запроса о заходе, данные о судне и разрешениях, информация об экипаже и грузе, о маршруте судна, включая районы промысла и т.д.

Другая инструкция должна детально определять порядок использования судами (в частности, иностранными) российских морских портов, например, она должна определять порядок выгрузки, перегрузки, упаковки и переработки рыбы. Инструкция должна определять процедуру принятия решений к судам, допустившим ННН рыбный промысел.
Правительство России должно утвердить также инструкцию для инспекторов. В частности, инспекторы должны удостовериться насколько это возможно в том, что имеющаяся на борту документация по идентификации судна и информация, касающаяся владельца судна, является верной. Он будет удостоверяться о подлинности разрешения на промысел. Инспектор будет осматривать орудия лова, трюмы и цеха. Инспектор оценит, имеются ли явные основания полагать, что судно принимало участие в $\mathrm{HHH}$ рыбном промысле или связанной с промыслом деятельности в поддержку такого промысла.

Отдельные вопросы, вытекающие из выполнения Соглашения 2009 г., должны быть урегулированы нормативными правовыми актами Минтранса России, Минсельхоза России и других федеральных органов исполнительной власти.

\section{ЛИТЕРАТУРА И ИСТОЧНИКИ}

1. Бекяшев Д.К., Оханов А.А. Итоги 32-й сессии Комитета по рыболовству ФАО и перспективы международного рыбохозяйственного сотрудничества / Д.К. Бекяшев, А.А.Оханов // Рыбное хозяйство. 2016. - №4. - С. 37-48.

1. Bekyashev D. K., Oganov A. A. the results of the 32nd session of the Committee on fisheries of FAO and the prospects for international fisheries cooperation / D. K. Bekyashev, A. A. Okhanov // fisheries. - 2016. - No. 4. - P. 37-48.

2. Предисловие Генерального директора ФАО // Соглашение о мерах государства порта по предупреждению, сдерживанию и ликвидации незаконного, несообщаемого и нерегулируемого промысла. Рим: ФАО, 2016. - 48 c.

2. Foreword by the Director General of FAO, / / the Agreement on port state measures to prevent, deter and eliminate illegal, unreported and unregulated fishing. Rome: FAO, 2016. - 48 p.

3. Doulman D., Swan J. A Guide to the Background and Implementation of the 2009 FAO Agreement on Port State Measures to Prevent, Deter and Eliminate Illegal, Unreported and Unregulated Fishing// FAO Fisheries and Aquaculrute Circular №1074 FAO. Rome. 2012. - 165 p.

4. Бекяшев К.А. Морское рыболовное право: учебник. - 3-е изд., доп. И испр. - Москва: Проспект. - 2021. - 640 с.

4. Bekyashev K. A. Sea fishing law: textbook. - 3rd ed., add. And ispr. Moscow: Prospekt. - 2021. - 640 p.

5. Бекяшев Д.К. Конвенция МОТ о труде в рыболовном секторе. Постатейный комментарий. Москва, 2008. - 188 с.

5. Bekyashev D. K. ILO Convention on Labour in the Fishing sector. Articleby-article comment. Moscow, 2008. - 188 p.

6. Бекяшев Д.К. Международно-правовые проблемы управления рыболовством: монография. - Москва Проспект, 2017. - 512 с.

6. Bekyashev D. K. International legal problems of fisheries management: monograph. - Moscow Prospekt, 2017. - 512 p.

7. Бекяшев К.А. Правовые основы рыболовной политики Российской Федерации на международной арене. / К.А. Бекяшев, Д.К. Бекяшев // Рыбное хозяйство. -2019. - №6. - С. 26-30.

7. Bekyashev K. A. Legal foundations of the fishing policy of the Russian Federation in the international arena. -2019. - No. 6. - pp. 26-30.

8. Илья Шестаков: ратификация Соглашения о мерах государства порта по борьбе с ННН-промыслом поможет предотвратить ущерб запасам Мирового океана и продовольственной безопасности страны [Электронный ресурс] // Режим доступа: http://fish. gov.ru/obiedinennaya-press-sluzhba/novosti/32171-ilya-shestakovratifikatsiya-soglasheniya-o-merakh-gosudarstva-porta-po-borbe-s-nnnpromyslom-pomozhet-predotvratit-ushcherb-zapasam-mirovogo-okeanai-prodovolstvennoj-bezopasnosti-strany (дата обращения 16.12.2020).

8. Ilya Shestakov: Ratification of the Agreement on Port State Measures to Combat IUU Fishing will help prevent damage to the World's ocean reserves and the country's food security [Electronic resource] // Access mode: http:// fish.gov.ru/obiedinennaya-press-sluzhba/novosti/32171-ilya-shestakovratifikatsiya-soglasheniya-o-merakh-gosudarstva-porta-po-borbe-s-nnnpromyslom-pomozhet-predotvratit-ushcherb-zapasam-mirovogo-okeana-iprodovolstvennoj-bezopasnosti-strany (accessed 16.12.2020). 